\title{
Impact of Video Clips on the Development of the Listening Skills in English Classes: A Case Study of Turkish Students
}

\author{
İnan Tekin ${ }^{1}$, Ramazan Şükrü Parmaksız ${ }^{2}$ \\ ${ }^{1}$ Bulent Ecevit University, Preparatory School of Foreign Languages, Zonguldak, Turkey \\ ${ }^{2}$ Bulent Ecevit University, Eregli Faculty of Education, Zonguldak, Turkey \\ Correspondence: İnan Tekin Preparatory School of Foreign Lang, Bulent Ecevit University, Zonguldak, Turkey.
}

Received: June 27, 2016 Accepted: July 19, $2016 \quad$ Online Published: August 3, 2016

doi:10.11114/jets.v4i9.1698 URL: http://dx.doi.org/10.11114/jets.v4i9.1698

\begin{abstract}
The purpose of this research is to examine whether using feature films in video lessons has an effect on the development of listening skills of students or not. The research has been conducted at one of the state universities in Black Sea region of Turkey with 126 students. The students watched and listened to only the sentences taken from categorized feature films. In the research, the Factorial Research Design, one of the quasi-experimental designs, was used. At the end of the research, it was found out that categories of the films did not make statistically significant difference in the success of the students while there was a statistically significant difference in the success of male students in each film categories with long length in respect of short replicas.
\end{abstract}

Keywords: language learning, listening skills, feature films in language learning, audio-visual materials

\section{Introduction}

\subsection{Introduce the Problem}

Nowadays, students are surrounded by information from several sources and reaching information becomes more important every day. In order to cope with the challenges of this intensity of information faced by students at school which they will also face in the business World, they need to develop different and more useful methods than those previously used. The reason for existence of students in Turkey who had received English training for years but cannot speak the language plays a significant role in the subjects studied. The skills of "speaking" and "listening" in learning a foreign language necessitate the students not only to add new vocal skills on the sounds they hear and innate but also to use those skills to understand the new voices they hear in the second language and try to spell that with a voice close to that language; and the purpose in teaching "listening" is to provide the students with an ability to recognize the sounds in a foreign language, to realize the changes in meaning caused by accenting and intonation and to understand the message coming from the speaker clearly and fully (Demirel, 2004). As Demirel (2004) and Aküzel (2006) have mentioned, the purpose of giving importance to listening skills and to conduct listening activities is to make the students give the accurate response in real cases and dialogs they will face in real life in which they will communicate by using their foreign language. When compared with other skills, listening activities should consist of activities closer to real life and the related evaluations and measurements. Listening activities conducted within the classroom are naturally not suitable for real life situations. Therefore, it will be more appropriate to provide the students with dialogs that include characteristics from real-life in order to make them understand the real life talks (Aküzel, 2006). Furthermore, according to Ur (1996), as only a few of real life speeches and talks are made just as reading a plain text out and normally we do not answer any comprehension questions after the speech to know whether we understand the daily life speeches or not, the listening studies in the classroom should not be based on texts or dialogs read which are followed by comprehension questions about these texts or dialogs afterwards. Also, it can be said that listening exercises with a closer perspective to real-life situations can be more attractive and motivating than fictional ones. On the other hand, one of the methods to build the listening skill for students in foreign language is teaching with videos. In video teaching, images accompany the sound and this encourages the students to become more motivated and interested in learning the language. That students listen to the dialogs on the screen accompanied visually in a meaningful environment is closer to the real life. Therefore, it could be suggested that providing the audiovisual characteristics together is very beneficial for students and video brings the real life into the classroom. Thus, students will both hear and see the speakers thanks 
to the video. In addition to this; they will have the opportunity to capture the background, linguistic tips and non-verbal communication (Wilkinson, 1984). Watts (1989) has observed that the students learning French in England have watched French TV series and this has helped the students getting actively engaged in the learning process and the learning process has become entertaining and it has generally increased the motivation and success of students in foreign language learning. The studies of Keene (2006) and Jeng, Wang and Huang (2009) on the videos' realistic contexts providing the students with acquisition of language; the study of Brown (2010) which uses authentic movies in order to make the students gain vocabulary learning skills; the study of Winnie (2010) that measures the understanding skill of students; the study of Gahlorei and Tabatabei (2011) on teaching the English idioms to students by making them watch short clips from movies and by using traditional methods are some examples on foreign language acquisition by using authentic movies. Video clips can help the students in various ways with the audiovisual knowledge transfer they provide. Some of these ways are having a main idea from the communicative situations in the video, to understand the meaning of words they do not know and to organize the linguistic structures and to establish a scheme for each situational context (Kitajima \& Lyman, 1998).

\subsection{Explore Importance of the Problem}

Foreign language teaching and learning is a multi-dimensional concept with a broad scope. According to Levy and Hubbard (2005), foreign language learning is hard due to the interrelated dimensions that need to be comprehended. Traditionally, foreign language teaching aims to improve four skills (reading, writing, listening, speaking) of students and the teachers mostly focus on making the students gain listening, understanding and communication skills which are more important for foreign language learning. The mostly used tools during this process are the multimedia technologies and the resources provided to education via this technology. A number of language educators (Cronbach \& Snow, 1977) have accepted that utilization of multimedia is indispensable in language learning. Teachers using multimedia in their lectures have indicated that this made their lectures more entertaining and interesting for students. Multimedia presents all emotional methods together and makes the students interact, therefore, it has been a significant tool for language learning. As utilization of multimedia attracts the attention of students due to audiovisual and real life situations; it has a huge impact on students' motivation and will of actively participating in language learning. In addition to these, Florence (2009) has stated that movies present the daily speaking language within their real contexts and therefore they are more valuable and richer sources than videos specifically designed for English teaching.

The primary goal of this study is to use video as one of the multimedia tools in order to measure the level of understanding for the sentence structures built by Simple Present Tense in the video clips extracted from authentic movies as a supplement for fictional videos used in English teaching and to research whether this has any impact on the listening skills of students or not.

\subsection{Sub problems}

1. Is there a difference in the success level of students according to categories of authentic movies (horror, adventure, drama)?

2. Is there a difference in the success level of students in terms of gender regarding the video clips extracted from authentic movies?

3. Is there a significant difference in the student success depending on the categories of authentic movies in the length of video clips extracted?

\section{Method}

In this section, research model, research group, data collection and data analysis are presented.

\subsection{Research Model}

One of the quasi-experimental study designs, the factorial design was used in this study (Creswell, 2002). The purpose of choosing this study design is to observe the impact of different experimental applications on experimental groups. By using the factorial study design, the impact of parts with different lengths from different movies on the success of students' understanding of what they hear was studied. The study design used in this research is illustrated in Table 1.

Table 1. Study design used in this research

\begin{tabular}{|c|c|c|c|}
\hline Experimental Implementations & Implementation 1 (Horror) & Implementation 2 (Adventure) & Implementation 3 (Drama) \\
\hline Measurement & DAB1 & DAB1 & DAB1 \\
\hline
\end{tabular}

DAB 2: Ability to Understand What They Hear (Long clips [6-20 words / up to 10 seconds])

Experimental Implementation 1: Implementation of understanding what they hear by using long and short parts 
extracted from authentic horror movies

Experimental Implementation 2: Implementation of understanding what they hear by using long and short parts extracted from authentic adventure movies

Experimental Implementation 3: Implementation of understanding what they hear by using long and short parts extracted from authentic drama movies

\subsection{Resarch Group and Data Collection}

Data for this research are obtained from three experimental groups participating in different implementations stated above. The data obtained from the determination of the impact of experimental transaction implemented to the groups on their ability to understand what they hear and the comparison of those are interpreted in terms of causality.

Within the scope of the implementation process, experiment groups have accessed to clips extracted from authentic movies with different content (Horror, adventure and drama) for a month at the laboratory courses in school. The students were asked to write down the sentences they heard from the clips. These sentences were compared with the original sentences from the clips, evaluated by using a gradual scoring scale and according to the number of words they wrote down accurately; thereby the differences at the level of understanding what they hear was determined.

\subsection{Data Analysis}

Moodle Internet-based course preparation system version 1.9.7 was used as the data gathering tool whereas gradual scoring scale (rubric) was used in order to determine the cases of understanding what they hear. Five item gradual scoring scale developed by the researcher and with the expert opinion was used to collect data. The gradual scoring scale with items is illustrated in Table 2.

Table 2. Gradual scoring scale

\begin{tabular}{ll}
\hline LEVEL & COMPETENCIES \\
\hline LEVEL 1 & $\begin{array}{l}\text { Student wrote down one or two words from the speech sentence, the sentence is meaningless. } \\
\text { Student wrote down approximately } 1 / 2 \text { of the words from the sentence, the sentence does not provide the full } \\
\text { meaning. }\end{array}$ \\
LEVEL 3 & $\begin{array}{l}\text { Student wrote down more than } 1 / 2 \mathrm{f} \text { the words from the sentence, the meaning of the sentence is almost there. } \\
\text { LEVEL } 4\end{array}$ \\
$\begin{array}{l}\text { Student has complete } 3 / 4 \text { of the sentence, with some misspelling in some words. The meaning of sentence is } \\
\text { apprehended. }\end{array}$
\end{tabular}

According to this scale, the score students will receive when they write down a sentence correct was determined by rating the number of accurately written words and the total number of words in the sentence. The process of evaluation can be summarized as below:

For Example: Evaluation for a student who wrote 3 out of 5 words in a sentence: Score for the accurate writing of a word: Total number of words in the sentence $/ 5 / 5 / 5=1$ Each correct word is 1 point. Student wrote 3 words accurately: The score will be $3 \times 1=3$. For Example: Evaluation for a student who wrote 8 out of 13 words in a sentence: Score for the accurate writing of a word: Total number of words in the sentence $/ 5 / 5 / 13=0.384$ Each correct word is 0.384 point. Student wrote 8 words accurately: The score will be $8 \times 0,384=3.07$. Calculated scores were rounded. Etc.: If the score after calculation was 4.40, it was evaluated as 4 ; whereas 4.60 was evaluated as 5 .

At the first phase of the experimental transaction, the classes to participate in implementation were determined. The implementation was carried out in all of the classes being taught at the same level of course in order to keep the foreign language levels closer to each other. To ensure the equality of foreign language levels, the current status was tested by reviewing the examination results of students and obtaining the opinions of lecturers.

The video clips that experimental groups watched passed through a long and rigorous preparatory phase before uploading into Moodle. These steps were followed:

a. The movies for sample groups were determined from the latest movies that will be watched with great interest.

b. Movies were selected by the researcher, and the appropriate ones were chosen suitable to use in implementation.

c. The parts of movies with Simple Present Tense were selected and the time range of these parts was determined. A total number of parts selected is 75 .

d. Selected parts were assembled by the researcher and transformed into video clips. They were grouped as long and short clips. Short clips consist of 1-5 words and long clips consist of 6-20 words.

e. 75 parts were reviewed again and 60 parts were included to the research on the basis of their suitability with the purpose of this implementation, suitability with the level of students and in accordance with the words suitable to Language Preparatory Program. 
After the selection and classification of clips were completed; categories of Horror, Adventure and Drama were generated in Moodle and under each category, study pages with 20 video clips (10 short, 10 long) were added. User accounts were generated for students' access to the content. Moodle program was programmed in a way to give the students only 5 attempts to watch and listen to the clip.

The collaboration was made with the teachers of participant classes and the students regularly participated in the application for 1 month. Students were made to watch the Horror, Adventure and Drama categories in an order and one by one. So, the implementation was more systematic. Periodical meetings were conducted with teachers, and directions were made about the challenging parts of implementation in order to manage the process better.

\section{Results}

This section includes the results reached by using the scores obtained by experimental groups by answering the computer-based video courses and the data obtained. Descriptive statistics of experimental groups, distribution of scores obtained from implementation, sub problems and the summary of findings were mentioned, in respective order. The descriptive statistics of scores for video categories are illustrated in Table 3.

Table 3. Descriptive Statistics of Scores For Video Categories

\begin{tabular}{llllll}
\hline Film Category & & N & X & Std. Dev. & Average Std. Deviation \\
\hline Horror & Short (N.W.) & 126 & 33,84 & 6.63 & 0,59 \\
& Long (N.W.) & 126 & 63.38 & 1,57 & 1,40 \\
& Short (N.W.) & 126 & 40.31 & 7,83 & 0.69 \\
Adventure & Long (S.P.) & 126 & 33.61 & 7,66 & 0,68 \\
& Short (N.W.) & 126 & 41,93 & 5,05 & 0,45 \\
& Long (N.W.) & 126 & 59,48 & 1,94 & 1.73 \\
Drama & Short (S.P.) & 126 & 44,59 & 5.39 & 0,48 \\
& Long (S.P.) & 126 & 32.23 & 9,28 & 0,82 \\
& Short (N.W.) & 126 & 33,32 & 4,27 & 0.38 \\
& Long (N.W.) & 126 & 53.13 & 1,34 & 1,19 \\
& Short (S.P.) & 126 & 41,36 & 5.37 & 0,47 \\
\hline$:$ Scon & Long (S.P..) & 126 & 36,03 & 9,31 & 0,82 \\
\hline
\end{tabular}

(N.W.): Score obtained from the accurately written number of words

(S.P.): Score obtained by using the Gradual Scoring Scale

The data obtained from the research were examined by conducting Kolmogorov-Smirnov test and it emerged that the data had a normal distribution for all the groups and the analysis was conducted by parametric tests.

\subsection{Results about the First Research Question}

"Is there a difference on the success level of students according to categories of authentic movies (horror, adventure, drama)?" was the first research question and One-way ANOVA was used to analyze this. The results of One-way ANOVA conducted for first research question is illustrated in Table 4.

Table 4. Results of One-way ANOVA For Movie Categories

\begin{tabular}{llllll}
\hline Source of Variance & Sum of Squares & sd & Averages of Squares & F & p \\
\hline Between Groups & 867.132 & 2 & 433.566 & 2.479 & 0.085 \\
Intragroups & 65593.810 & 375 & 174.917 & & \\
Total & 66460.942 & 377 & & \\
\hline
\end{tabular}

$* \mathrm{p}<0.05$

As it can be seen from one-way ANOVA results, there is no significant difference between the video categories students watched within the scope of implementation and their level of success $F(2,375)=2.47 ; p>0.05$. The success of students did not change according to film categories. It can be said that the development of listening abilities of students did not differ according to movie genres watched.

\subsection{Results about the Second Research Question}

"Is there a difference on the success level of students in terms of gender regarding the video clips extracted from authentic movies?" was the second research question and t test was implemented for independent groups. Results are illustrated in Table 5. 
Table 5. Independent Sample T-Test Results of Participants in Drama Category According to Gender

\begin{tabular}{lllllllll}
\hline Category & Gender & N & X & SS: & Sd & t & p \\
\hline Short & Girl & 72 & 40.65 & 6.04 & 124 & -1.732 & .086 \\
& Boy & 54 & 42.31 & 4.18 & & & \\
Long & Girl & 72 & 34.58 & 9.42 & 124 & -2.041 & $.043^{*}$ \\
& Boy & 54 & 37.96 & 8.89 & & & \\
\multirow{2}{*}{ Total } & Girl & 72 & 75.23 & 13.17 & 124 & -2.246 & $.026^{*}$ \\
& Boy & 54 & 80.27 & 11.46 & & & \\
\hline
\end{tabular}

$* \mathrm{p}<0.05$

It was observed that the average score of the females on short clips in the drama category was $40.65(\mathrm{~S}=6.04)$ and the average score for males was $42.31(\mathrm{~S}=4.18)$. In other words, there was no significant difference between the scores of male and female participants in short clips under the drama category $(\mathrm{t}(124)=-1.732 ; \mathrm{p}>0.05)$. Similarly, it was observed that the average score of the females on long clips in the drama category was $34.58(\mathrm{~S}=9.42)$ and the average score for males was $37.96(\mathrm{~S}=8.89)$. It was determined that there was a difference between the scores of male and female participants in long clips in terms of male participants $(t(124)=-2.041 ; \mathrm{p}<0.05)$. It was observed that the average score of the females in total score was $75.23(\mathrm{~S}=13.17)$ and the average score for males was 80.27 ( $\mathrm{S}=11.46)$. In addition to these it was revealed that the difference between averages was statistically not significant $(\mathrm{p}, 0.026<0.05)$. In other words, there was a significant difference between the male and female participants under the drama category in favor of male participants $(\mathrm{t}(124)=-2.246 ; \mathrm{p}>0.05)$.

Table 6. Independent Sample T-Test Results of Participants in Horror Category According to Gender

\begin{tabular}{llllllll}
\hline Category & Gender & N & X & SS: & Sd & t & p \\
\hline Short & Girl & 72 & 40.83 & 8.03 & 124 & -.386 & .700 \\
& Boy & 54 & 40.62 & 7.61 & & & \\
Long & Girl & 72 & 32.27 & 7.41 & 124 & -2.308 & $.023^{*}$ \\
& Boy & 54 & 35.40 & 7.68 & & & \\
Total & Girl & 72 & 72.36 & 13.10 & 124 & -1.516 & .132 \\
& Boy & 54 & 75.03 & 13.95 & & & \\
\hline
\end{tabular}

$* \mathrm{p}<0.05$

It was observed that the average score of the females on short clips in horror category was $40.3(\mathrm{~S}=8.03)$ and the average score for males was 40.62 ( $S=7.61)$. In other words, there was no significant difference between the scores of male and female participants in short clips $(\mathrm{t}(124)=-.386 ; \mathrm{p}>0.05)$. It was observed that the average score of the females on long clips was $32.27(\mathrm{~S}=7.41)$ and the average score for males was $35.40(\mathrm{~S}=7.68)$. In other words, there was a significant difference between the male and female participants under the Horror category in favor of male participants $(t(124)=-2.308 ; \mathrm{p}<0.05)$. It was observed that the average score of the females in total score was $72.36(\mathrm{~S}=13.10)$ and the average score for males was $75.03(\mathrm{~S}=13.95)$. In other words, there was no significant difference between the scores of male and female participants in terms of total scores under the drama category $(t(124)=-1.516 ; p>0.05)$.

Table 7. Independent Sample T-Test Results of Participants in Adventure Category According to Gender

\begin{tabular}{lllllllll}
\hline Category & Gender & N & X & SS: & Sd & t & p \\
\hline Short & Girl & 72 & 43.65 & 5.75 & 124 & -2.303 & $.023^{*}$ \\
& Boy & 54 & 45.85 & 4.62 & & & \\
& Long & Girl & 72 & 30.41 & 9.21 & 124 & -2.589 & $.011^{*}$ \\
& Boy & 54 & 34.64 & 8.89 & & & & \\
& Total & Girl & 72 & 74.06 & 13.68 & 124 & -2.724 & $.007 *$ \\
& Boy & 54 & 80.50 & 12.30 & & & & \\
\hline
\end{tabular}

$* \mathrm{p}<0.05$

It was observed that the average score of the females on short clips in adventure category was $43.65(\mathrm{~S}=5.75)$ and the average score for males was $45.85(\mathrm{~S}=4.62)$. It emerged that there was a difference between the scores of male and female participants in short clips in favor of male participants $(\mathrm{t}(124)=-2.303 ; \mathrm{p}<0.05)$. It was observed that the average score of the females on long clips was $30.41(\mathrm{~S}=9.21)$ and the average score for males was $34.64(\mathrm{~S}=8.89)$. Additionally, it was found out that there was a difference between the scores of male and female participants in long clips in favor of male participants $(\mathrm{t}(124)=-2.589 ; \mathrm{p}<0.05)$ and the average score of the females in total score was $74.06(\mathrm{~S}=13.68)$ while it was $80.50(\mathrm{~S}=12.30)$ for males. It was also found out that the difference between averages was statistically significant $(\mathrm{p}, 0.0076<0.05)$. In other words, there was a significant difference between the male and female participants under the Adventure category in favor of male participants $(t(124)=-2.724 ; p>0.05)$. Therefore, it 
can be concluded that male students easily used their ability to understand what they listened as they are considered to be more addicted to Adventure movies.

\subsection{Results about the Third Research Question}

"Is there a significant difference in the student success depending on the categories of authentic movies $n$ the length of video clips extracted?" was the third research question and One-way ANOVA was used to analyze this. The results of One-way ANOVA conducted for third research question is illustrated in Table 8.

Table 8. Results of One-way ANOVA for the Number of Words in Videos

\begin{tabular}{llllll}
\hline \multicolumn{4}{l}{ Source of VarianceSum of Squaressd } & \multicolumn{1}{l}{ Averages of SquaresF } & p \\
\hline Between Groups & 155329.637 & 11 & 14120.876 & $135.9970 .000^{*}$ \\
Intragroups & 155748.643 & 1500 & 103.832 \\
Total & 311078.820 & 1.511 & \\
\hline
\end{tabular}

$* \mathrm{p}<0.05$

As it can be seen from one-way ANOVA results, there was a significant difference between the number of words in the videos watched within the scope of implementation and their level of success $F(11,1500)=135.997 ; p>0.05$. The success of students in the implementation changed according to the number of words in the video. It can be said that the amount of words created a difference on the skill to understand. Tukey, one of the Post-hoc tests (Table 9) revealed where the difference was among videos at different categories and length.

Table 9. Impact of Film Categories and Clip Length on Success- Results of Tukey Test

\begin{tabular}{|c|c|c|c|c|c|c|}
\hline \multirow{2}{*}{\multicolumn{2}{|c|}{ (I) Group }} & \multirow[t]{2}{*}{ (J) Group } & \multirow[t]{2}{*}{$\begin{array}{l}\text { Average } \\
\quad \text { Difference(I-J) }\end{array}$} & \multirow[t]{2}{*}{$\begin{array}{l}\text { Standard } \\
\text { Deviation }\end{array}$} & \multicolumn{2}{|c|}{$\begin{array}{l}\mathbf{9 5 \%} \\
\text { interval }\end{array}$} \\
\hline & & & & & $\begin{array}{l}\text { Lower } \\
\text { Bound }\end{array}$ & $\begin{array}{l}\text { Upper } \\
\text { Bound }\end{array}$ \\
\hline \multirow{2}{*}{\multicolumn{2}{|c|}{$\overline{\text { Horror Short (N.W.) }}$}} & \multicolumn{2}{|c|}{ Long-25,642 } & 1,283 & $0,000 *-29,845$ & $-21,440$ \\
\hline & & \multicolumn{2}{|c|}{ Drama Long (N.W.) $-19,293$} & 1,283 & $0,000 *-23,495$ & $-15,091$ \\
\hline \multirow{2}{*}{\multicolumn{2}{|c|}{ Horror Long (N.W.) }} & \multicolumn{2}{|c|}{ Short 21,444} & 1,283 & $0,000 * 17,242$ & 25.646 \\
\hline & & Drama Short (N.W.) & 30,055 & 1,283 & $0,000 * 25,853$ & 34,257 \\
\hline \multirow{2}{*}{\multicolumn{2}{|c|}{ Horror Short (S.P.) }} & \multicolumn{2}{|c|}{ Adventure Long (S.P.) 8,087 } & 1,283 & $0,000 * 3,885$ & 12,289 \\
\hline & & Dram Long (S.P.) & 4,285 & 1,283 & $0041 * 0,083$ & 8,847 \\
\hline \multirow{2}{*}{\multicolumn{2}{|c|}{ Horror Long (S.P.) }} & \multicolumn{2}{|c|}{ Adventure Short (S.P.)-10,976 } & 1,283 & $0,000 *-15,178$ & $-6,774$ \\
\hline & & Drama Short (S.P.) & $-7,746$ & 1,283 & $0,000 *-11,948$ & $-3,543$ \\
\hline \multirow{2}{*}{$\begin{array}{l}\text { Adventure } \\
\text { (N.W.) }\end{array}$} & \multirow[t]{2}{*}{ Short } & Horror Long (N.W.) & $-21,444$ & 1,283 & $0,000 *-25,646$ & $-17,242$ \\
\hline & & Drama Long (N.W.) & $-11,198$ & 1,283 & $0,000 *-15,400$ & $-6,996$ \\
\hline \multirow{2}{*}{$\begin{array}{l}\text { Adventure } \\
\text { (N.W.) }\end{array}$} & \multirow[t]{2}{*}{ Long } & Horror Short (N.W.) & 25,642 & 1,283 & $0,000 * 21,440$ & 29,845 \\
\hline & & Drama Short (N.W.) & 26,158 & 1,283 & $0,000 * 21,956$ & 30,360 \\
\hline \multirow{2}{*}{$\begin{array}{l}\text { Adventure } \\
\text { (S.P.) }\end{array}$} & \multirow[t]{2}{*}{ Short } & Horror Long (S.P.) & 10,976 & 1,283 & $0,000 * 6,774$ & 15,178 \\
\hline & & Drama Long (S.P.) & 8,563 & 1,283 & $0,000 * 4,361$ & 12,765 \\
\hline \multirow{2}{*}{$\begin{array}{l}\text { Adventure } \\
\text { (S.P.) }\end{array}$} & \multirow[t]{2}{*}{ Long } & Horror Short (S.P.) & $-8,087$ & 1,283 & $0,000 *-12,289$ & $-3,885$ \\
\hline & & Drama Short (S.P.) & $-9,134$ & 1,283 & $0,000 *-13,337$ & $-4,932$ \\
\hline \multirow{2}{*}{\multicolumn{2}{|c|}{ Drama Short (N.W.) }} & Horror Long (N.W.) & $-0,293$ & 1,283 & $1,000-4,495$ & 3,908 \\
\hline & & Adventure & $-26,158$ & 1,283 & $0,000 *-30,360$ & $-21,956$ \\
\hline \multirow{2}{*}{\multicolumn{2}{|c|}{ Drama Long (N.W.) }} & Horror Short (N.W.) & 19,293 & 1,283 & $0,000 * 15,091$ & 23,495 \\
\hline & & Adventure & $\mathrm{t} 11,198$ & 1,283 & $0,000 * 6,996$ & 15,400 \\
\hline \multirow{2}{*}{\multicolumn{2}{|c|}{ Drama Short (S.P.) }} & Horror Long (S.P.) & 7,746 & 1,283 & $0,000 * 3,543$ & 11,948 \\
\hline & & Adventure Long (S.P. & 9,134 & 1,283 & $0,000 * 4,932$ & 13,337 \\
\hline \multirow{2}{*}{\multicolumn{2}{|c|}{ Drama Long (S.P.) }} & Horror Short (S.P.) & $-4,285$ & 1,283 & $0041 *-8,487$ & $-0,083$ \\
\hline & & Adventure Short (S.P. & $-8,563$ & 1,283 & $0,000 *-12,765$ & -4.361 \\
\hline
\end{tabular}

$* \mathrm{p}<0.05$, (N.W.): Score obtained from the Accurately written number of words

(S.P.): Score obtained by using the Gradual Scoring Scale

When Table 9 is analyzed, it seems obvious that there was a significant difference among the points obtained from all movie sequences, except for one category $(\mathrm{p}=0.000)$. Only the score for drama short length clips evaluation and horror long length clips evaluations did not reveal any significant differences $(p=1.000)$. According to the length of movie segments, there was a significant difference between the success of students in terms of short length clips. Therefore it can be concluded that movie categories and length had an impact on the student success in terms of understanding what they listen. 


\section{Discussion and Conclusion}

This study was examined the level of impact of clips extracted from authentic movies with different categories (horror, adventure, drama) and different length (long and short) on the listening skill levels of students. The primary conclusions reached in the study are:

There was no significant difference between the categories of authentic movies (horror, adventure, drama) and the success of students. There was a significant difference in favor of male students in short and long sequences and total score for the skill of understanding what they listen. There was a significant difference in favor of short clips, depending on the length of speech texts in video clips extracted from authentic movies. There was a significant difference on the student success depending on the categories of authentic movies in the length of video clips extracted. It was observed that there was no significant difference only in the score obtained for drama short word number evaluation and horror long word number evaluation. Similar studies related to the research problems of this study can be evaluated, the results can be put under three titles and the reasons can be revealed.

The main reason why the clips extracted from movies with different categories (horror, adventure, drama) did not have any significant impact on student success in terms of improving the listening capability may be the short sequence of clips and that the students' inability to understand the category of movies while they were watching the clip. Although one of the categories was named as long clips, the clip with the longest duration was about 7-10 seconds. So this was not sufficient to notice the category of the movie and to impact the success level according to movie category. Yet, in terms of improving the ability to listen, as stated by Hemei (1997) "a two-minute length video might be equal to one hour of class study; or a ten minute length program might be very useful for advanced level students."

On the other hand, it is possible to indicate that students are interested in popular horror, adventure and drama category and that each movie category will have the equal interest. Considering the fact that the types of short clips do not make a significant difference in the improvement of listening skill; it can be suggested that movies in each category are liked by teachers and students due to their rich content and students' motivation were at high levels no matter what the type of clip presented is (Hemei, 1997).

The study also indicated that participants had a higher level of success in terms of listening skill when they worked with short clips. The main reason of this was that the students had recently started to learn a foreign language and this might have caused them a problem to remember and understand long sentences they listened. According to Stempleski (1992), videos shorter than five minutes are usually enough for students who learn a foreign language. Chapters with two or three minutes might have an equal impact of other learning materials used during one hour of lecture. It should also be considered that this was the first time for students to engage in authentic movies. Implementing some courses at video lectures with authentic movies might make the students more familiar with the communication world in here. Jimin (2007) has stated that the presentation of audiovisual elements such as videos to students via computer technologies makes it easier for students to acquire the information and also contributes to students' period of retaining this information. Therefore, the failure in long clips during the study might have appeared due to the students' lack stemming from their first experience because as the length of clip increased, students success decreased. It can be inferred that this is normal for students who have a low-medium level of foreign language knowledge.

Another important point is their lack of using the proper listening strategies which will provide them success in listening processes. Listening strategies are the methods used when the understanding process is interrupted at any time during listening; to solve the problem and turn the process into a full and complete meaning (Chamot, 1995). It is hard to assume that participants with a low-middle level of English will be successful in long clips without using these methods.

Another reason of failure in long clips might be that the participants could not establish a scheme in their listening processes. According to Rumelhart (1980), a scheme is "the information structure used to represent the general concepts stored in memory". Audience uses linguistic and situational tips and even assumptions in order to create new schemes in his/her mind about the new information. But it is possible to say that the students in the study group do not have command on linguistic situations and therefore they could not evaluate the tips and make assumptions, which reveals the responsibility of teacher for choosing the appropriate video. Valderrama, Ocana and Sheremetov (2005) have indicated that it is hard to find the most appropriate films related with the subject, word and grammar structure to be taught to children and that there is still no systematic way. For instance "heading for" is a very widely used concept in English which we hear in movies a lot; and that it will be very beneficial for students to hear and see this within the context of a movie.

Teachers can choose "single scene approach" or "selective approach" for transferring information in a short time by using movies (Florence, 2009). In addition to this, students can become more familiar with any sentence established by English grammar structure at the courses where teachers use fictional (teaching) videos by stopping, rewinding, 
replaying and focusing on samples of usage; thereby helping the students to remember it for longer time periods and using them in sample sentences. Teachers have to consider the levels of foreign language and readiness of students while deciding on length and content intensity.

According to the results of this study; significant differences were observed in short and long movie sequences and the total score obtained from these sequences in favor of male students. The reason of this can be explained by the level of interest and readiness of female and male students for this implementation; although the listening skills of female students are better than male students (Eisenstein, 1982). Krendl, Broihier and Fleetwood (1989) have emphasized that male students are more inclined to use computers when compared with female students. So in this study the lower level of female students to study in computer environment when compared with male students, or the possibility that adventure, horror or drama movies within the categories were not points of interest for them before could be some reasons for male students to be more successful. Another reason of this might be that the female students' effort to translate the lines they listened into Turkish in their minds. It might be possible for them to miss the real meaning while trying to translate.

\section{Recommendations}

The study can be repeated on different groups by choosing different movie categories. This might reveal the effectiveness of authentic movies on language learning. The success of male students in understanding what they listen for authentic movies can be in-depth analyzed in other studies. Additional categories such as medium, upper medium and advanced levels might be added to two movie length categories (long and short) and different clips with different number and duration of words with different levels might be developed. By doing so, the competencies of students in terms of understanding what they listen and English grammar can be measured by different implementation forms.

Participants could only access the application at laboratory courses. This application can be carried at the Internet and mobile environment and the students can access the videos any time they wish, which might be a subject of research whether this will have an impact on success level or not. The words and grammar structures within the authentic movies used in the application can be diversified, transformed into an audiovisual dictionary and grammar application via an appropriate computer program and might be presented as a useful source for students who learn English.

\section{References}

Aküzel, G. (2006). İlköğrertim 4-8. Sınıflarda Yabancı Dil Öğretimindeki Başarısızlık Nedenlerinin İncelenmesi (Unpublished master's thesis). Çukurova Üniversitesi Sosyal Bilimler Enstitüsü, Adana.

Brown, S. K. (2010). Popular Films in the EFL Classroom: Study of Methodology. Procedia Social and Behavioral Sciences, 3(2010), 45-54. http://dx.doi.org/10.1016/j.sbspro.2010.07.011

Chamot, A. U. (1995). Learning Strategies and Listening Comprehension, A Guide for the Teaching of Second Language Listening. In D. Mendelsohn \& J. Rubin (Eds.), San Diego, CA, Dominie Press.

Cresswell, J. W. (2002). Research Design: Qualitative, Quantitative and Mixed Methods Approaches. SAGE Publications, U.S.A.

Cronbach, L. J., \& Snow, R. E. (1977). Aptitudes and Instructional Methods. Irvington, New York.

Demirel, Ö. (2004). Yabancı Dil Öğretimi, Dil Pasaportu Dil Biyografisi Dil Dosyası. Pegem Yayınları, Ankara.

Eisenstein, M. (1982). A Study of Social Variation in Adult Second Language Acquisition. Language Learning, 32(4), 367-391. http://dx.doi.org/10.1111/j.1467-1770.1982.tb00977.x

Florence, Y. K. Y. (2009). Learning English Through Films: A Case Study of a Hong Kong Class (Unpublished master's thesis ). For the Degree of Master of Arts in Applied Linguistics, Hong Kong.

Gahloeri, R. F., \& Tabatabaei, O. (2011). The Contribution of Movie Clips to Idiom Learning Improvement of Iranian EFL Learners. Theory and Practice in Language Studies, 1(8), 990-1000.

Hemei, J. (1997). Teaching with Video in An English Class. Journal of English Teaching Forum, 35(2), 45-47.

Jeng, Y., Wang, K., \& Huang, Y. (2009). Retrieving video Features for Language Acquisition. Expert System with Applications, 36(3), 5673-5683. http://dx.doi.org/10.1016/j.eswa.2008.06.117

Jimin, L. (2007). An Attempted Evaluation of Computer Assisted Language Learning in China. Canadian Social Science, 3(3), 109-113.

Keene, D. M. (2006). Viewing Video and DVD in the EFL Classroom. Bunkyo Gaukuin University Journal, 8(1), 217-234.

Kitajima, R., \& Lyman-Hager, M. A. (1998). Theory-Driven Use of Digital Video in Foreign Language Instruction. 
Calico Journal, 16(1), 37-48.

Krendl, K. A., Broihier, M. C., \& Fleetwood, C. (1989). Children and Computers: Do Sex-related Differences Persit?. Journal of Communication, 39(3), 85-93. http://dx.doi.org/10.1111/j.1460-2466.1989.tb01042.x

Levy, M., \& Hubbard, P. (2005). Why call CALL CALL? Computer Assisted Language Learning, 18(3), $143-149$. http://dx.doi.org/10.1080/09588220500208884

Rumelhart, D. (1980). Schema: The Basic Building Blocks of Cognition. In R. Spiro, B. Brice \& W. Brewer (Eds.), Theoretical Issues in Reading Comprehension. Hillsdale, NJ, Erlbaum.

Stempleski, S. (1992). Teaching Communication Skills with Authentic Video. In S. Stempleski \& P. Arcario (Eds.), Video in Second Language Teaching: Using, Selecting, and Producing Video for the Classroom. Alexandria, VA.

Ur, P. (1996). A Course in Language Teaching. Cambridge University Press, New York.

Valderrama, R., P., Ocana, L. B., \& Sheremetov L. B. (2005). Development of Intelligent Reusable Learning Objects for Web-Based Education Systems. Expert System with Applications, 28(2), 273-283.

http://dx.doi.org/10.1016/j.eswa.2004.09.003

Watts, C. (1989). Interactive Video: What the Students Say, CALICO Journal, 7(1).

Wilkinson, R. (1984). Video-Based Learning Activities. TESL Canada Journal, 1(2), 83-86. http://dx.doi.org/10.18806/tesl.v1i2.440

Winnie, S. W. M. (2010). Meaning representation In Video Outcomes of Inquiry Project. Computers \& Education, 55(4), 1532-1541. http://dx.doi.org/10.1016/j.compedu.2010.06.019

This work is licensed under a Creative Commons Attribution 3.0 License. 